\title{
Prevention of ventricular fibrillation by bretylium in a conscious canine model of sudden coronary death
}

\begin{abstract}
In anesthetized dogs, a silver wire electrode was inserted into the lumen of the circumflex coronary artery (LCX) and myocardial infarction was produced by a temporary 90-minute occlusion of the left anterior descending coronary artery (LAD) followed by reperfusion. Four days later while in the ambulatory state, a $150 \mu \mathrm{A}$ current was applied to the intimal surface of the LCX of saline $(n=10)$ and bretylium $(n=10)$ treated animals. Intimal injury and coronary thrombosis produced ST segment changes at $138 \pm 39$ minutes $(\chi \pm$ SEM), followed by premature ventricular beats (at $142 \pm 37$ minutes), ventricular tachycardia (at $156 \pm 49$ minutes), and ventricular fibrillation (at $163 \pm 51$ minutes) in 9 of 10 saline-treated animals. In bretylium-treated animals, ST segment changes appeared at $128 \perp 35$ minutes, with six animals surviving for 24 hours ( $p<0.03$ vs saline). LAD infarction was present in both saline $(14.1 \pm 2.3 \%)$ and bretylium $(15.1 \pm 2.1 \%$ of left ventricle) treated animals with only bretylium-treated animals developing $L C X$ infarcts $(16.1 \pm 2.1 \%)$. Bretylium prevents ventricular fibrillation (VF) resulting from ischemia at a site distant to prior myocardial infarction in the conscious dog and deserves further attention as a potential antifibrillatory agent for prevention of sudden coronary death in man. (AM HEART J 105:711, 1983.)
\end{abstract}

Kurt Holland, B.S., Eugene Patterson, Ph.D., and Benedict R. Lucchesi, Ph.D., M.D. Ann Arbor, Mich.

The high incidence of sudden coronary death in the United States and the failure of current antiarrhythmic drug therapy to prevent total events suggests a need to develop new antifibrillatory drugs capable of preventing unexpected death due to ventricular fibrillation. Bretylium tosylate, a quaternary ammonium antiarrhythmic agent, possesses antifibrillatory properties which may make it a suitable agent for the prevention of ventricular fibrillation in humans. Bretylium increases the electrical threshold for induction of ventricular fibrillation in the dog under normal physiologic conditions $\mathbf{s}^{1,2}$ and during acute myocardial ischemia. ${ }^{3,4}$ Bretylium also

From the Department of Pharmacology, The University of Michigan Medical School.

Supported by a grant from the National Institutes of Health, Hcart, Lung and Blood Institute, Grant No. HL-05806-22. Dr. Holland is a recipient of a Michigan Heart Association Medical Student Research Fellowship.

Received for publication Dec. 15, 1981; revision received Apr. 14, 1982; accepted Apr. 21, 1982.

Reprint requests: Benedict R. Lucchesi, M.D., Dept. of Pharmacology, M6322 Medical Science Bldg. I, The University of Michigan Medical School, Ann Arbor, MI 48109. protects against ventricular fibrillation occurring from coronary artery occlusion and reperfusion. ${ }^{2}$ While it is not possible to extrapolate these results readily to humans, bretylium has been shown to be effective in suppressing ventricular tachycardia and ventricular fibrillation occurring after cardiac surgery or during acute myocardial infarction. ${ }^{5-7}$ Bretylium can also suppress ventricular tachycardia produced in conscious dogs by programmed electrical stimulation during the convalescent phase of myocardial infarction. ${ }^{8,9}$ Although these studies might suggest an antifibrillatory action of bretylium, little is known about the ability of the drug to prevent the spontaneous development of ventricular fibrillation in the presence of myocardial ischemic injury-a situation more analogous to the clinical event of sudden coronary death.

Recently we described a conscious canine model of sudden coronary death which is marked by the spontaneous development of ventricular fibrillation, a result of acute myocardial ischemia in the presence of previous myocardial infarction. ${ }^{10}$ In the present study we examined the ability of bretylium to 
prevent ventricular fibrillation in this conscious canine model of sudden coronary death. The results of this investigation provide evidence that the quaternary ammonium drug, bretylium, has an ability to prevent the development of ventricular fibrillation in response to an acute ischemic event at a site remote from a previous infarct.

\section{METHODS}

Surgical preparation. Male mongrel dogs weighing between 14 and $22 \mathrm{~kg}$ were anesthetized with intravenous sodium pentobarbital $(30 \mathrm{mg} / \mathrm{kg})$. A cuffed endotracheal tube was inserted and the animals were ventilated with room air using a Harvard respirator. Under aseptic conditions, a cannula was inserted into the left external jugular vein and exteriorized at the back of the neck. A left thoracotomy was performed in the fourth intercostal space and the heart was suspended in a pericardial cradle. Using blunt dissection, the left anterior descending coronary artery was isolated free from surrounding myocardium at the tip of the left atrial appendage. Coronary artery flow was measured with an electromagnetic flow probe. A hypodermic needle with a blunted end was placed parallel to the coronary artery and a suture was passed around both the coronary artery and the needle. The suture was tied securely and the needle was withdrawn, thereby producing a critical stenosis. The needle size was adjusted so that the maximal hyperemic response to a 10 -second occlusion of the coronary artery was reduced by $60 \%$ or more without reducing resting coronary artery flow. The left anterior descending coronary artery was then occluded using a snare formed from a loop of silicone rubber tubing passed through a blunt-ended polyethylene tube. After 90 minules, the occlusive snare was removed and flow was restored through the stenosed artery.

The proximal $5 \mathrm{~mm}$ of the left circumflex coronary artery was isolated and the tip of a 30-gauge insulated silver wire was inserted through the wall into the vessel lumen. A bipolar electrode (25-gauge insulated stainless steel wire, 4 to $5 \mathrm{~mm}$ in length, $2 \mathrm{~mm}$ apart) was placed into the interventricular septum adjacent to the right ventricular outflow tract and silver electrodes were implanted subcutaneously for monitoring of a lead II ECG. The chest was closed in layers and the animals received intramuscular ampicillin $(10 \mathrm{mg} / \mathrm{kg})$.

Drug administration. On day three after myocardial infarction, normal sinus rhythm had returned and the animals were allocated randomly to one of two treatment groups in a double-blind fashion. One group received intravenous saline ( $20 \mathrm{ml}$ ) every 12 hours for four doses and the second group received bretylium tosylate, 10 $\mathrm{mg} / \mathrm{kg}$ in $20 \mathrm{ml}$ saline, every 12 hours for four doses. After 24 hours of treatment ( 12 hours after the second dose and immediately before the third dose), programmed electrical stimulation was performed while the animal was conscious and resting comfortably in a sling.

After administration of the third treatment dose, an anodal current of $150 \mu \mathrm{A}$ was applied to the intimal surface of the left circumflex coronary artery. Twelve hours later, the final (fourth) treatment dose was admin istered and the anodal current was discontinued.

Programmed electrical stimulation. Programmed electrical stimulation was performed while the animal was conscious and was resting comfortably in a sling. Premature stimuli ( $4 \mathrm{msec}$ duration, two times diastolic threshold) were introduced into the interventricular septum using a Grass S-88 stimulator and SIU-5 stimulus isolation unit. A Tektronix 565 oscilloscope with type $3 \mathrm{~A} 8$ operational amplifier was used to trigger the ventricular stimulus from the $\mathrm{R}$ wave of the lead II ECG

The programmed electrical stimulation procedure used is summarized below. (1) Single premature ventricular stimuli $\left(\mathrm{S}_{2}\right)$ at two times diastolic threshold were introduced during normal sinus rhythm at decreasing $10 \mathrm{msec}$ intervals from $350 \mathrm{msec}$ until ventricular refractoriness developed. (2) Double premature ventricular stimuli $\left(\mathrm{S}_{2}\right.$, $S_{3}$ ) at two times diastolic threshold were introduced during normal sinus rhythm at decreasing 10 msec intervals for $S_{2}$ stimuli from 350 msec until ventricular refractoriness developed with $S_{4}-S_{3}$ intervals of $200,180,170$, $160,150,140,135$, and $130 \mathrm{msec}$. (3) Triple premature ventricular stimuli $\left(S, S_{3}, S_{4}\right)$ at two times diastolic threshold were introduced during normal sinus rhythm at decreasing 10 msec intervals for $S_{2}$ siumuli from 350 msec until ventricular refractoriness developed with $S_{2}-S_{: 3}$ and $S_{-1}-S_{4}$ intervals as stated above. (4) Intermittent ventricular pacing (three to eight beats, two times diastolic threshold) at constant rates of 250,330 , and $360 \mathrm{bpm}$ was applied.

Previous studies have shown that this method of programmed electrical stimulation fails to produce ventricular arrhythmias in sham-operated animals without previuus myocardial infarction." Programmed stimulation was discontinued when ventricular tachycardia was reproduced in triplicate or when the entire stimulation procedure was completed. The lead II ECG was recorded continuously on a Grass model 7 polygraph and was stored on magnetic tape. The effective refractory period of normal left ventricular myocardium was determined at two times diastolic threshold $(4 \mathrm{msec}$ duration square wave pulse).

Initiation of current flow to the intimal surface of the left circumflex coronary artery. Immediately after drug administration (dose 3), an anodal direct current of $150 \mu \mathrm{A}$ was applied to the electrode previously inserted into the left circumflex coronary artery. The current source was a 9 $\mathrm{V}$ battery placed in series with a $250 \mathrm{k} \Omega$ potentiometer. The cathode was a silver disc electrode $(5 \mathrm{~mm}$ diameter) previously implanted subcutaneously. Electrical stimulation of the intimal surface was continued for 12 hours. The lead II ECG was transmitted from the conscious ambulatory dog via radiotelemetry and recorded continuously on magnetic tape for 12 hours followed by intermittent sampling ( 28 seconds of recording every 15 minutes) for an additional 12 hours.

Twenty-four hours after initiation of current flow to the intimal surface of the left circumflex coronary artery, the 


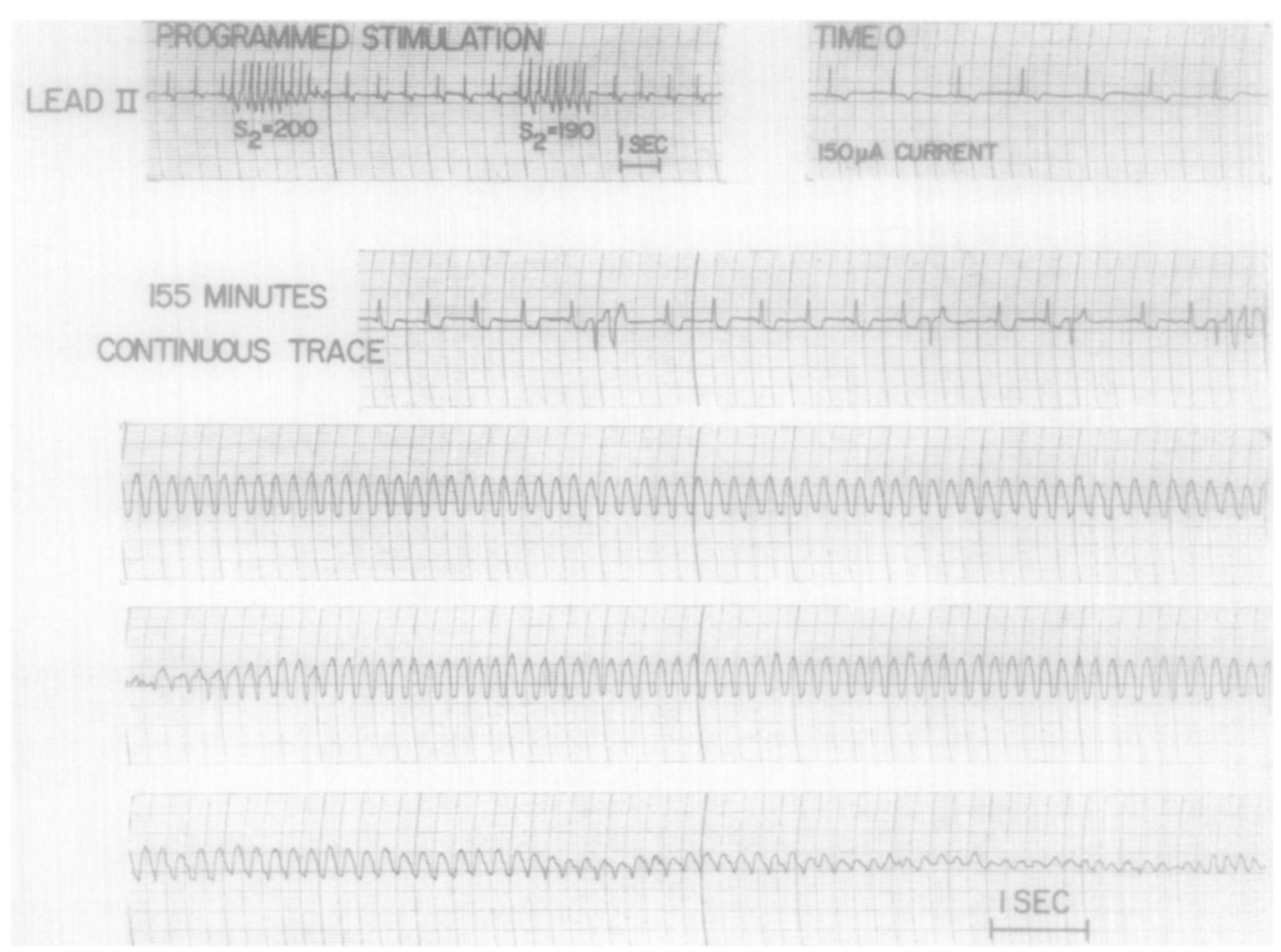

Fig. 1. Ventricular fibrillation in a conscious canine model of sudden coronary death. Programmed electrical stimulation (upper left panel) using single premature ventricular stimuli produced nonsustained ventricular tachycardia on day 4 after anterior myocardial infarction. Normal sinus rhythm immediately prior to initiating current flow to the intimal surface of the left circumflex coronary artery is shown in the upper left panel. At 150 minutes, ST segment depression becomes apparent (not shown). At 155 minutes, a ventricular couplet, ventricular tachycardia, and ventricular fibrillation develop.

surviving animals were killed with an overdose of sodium pentobarbital. The heart was removed and sectioned into $1 \mathrm{~cm}$ rings from apex to base, parallel to the atrioventricular groove. The sections wcre placed into $0.5 \%$ triphenyltetrazolium chloride in $0.1 \mathrm{M}$ potassium phosphate buffer, $\mathrm{pH}$ 7.4. Infarct size was determined gravimetrically. The left circumflex coronary artery was removed by careful dissection and was examined for the presence of thrombosis.

Statistics. Differences in survival rates between groups were analyzed by the Fisher exact test. Differences between groups were determined by a one-way analysis of variance. A value of $p<0.05$ was selected as the criterion for significance. Data are expressed as mean \pm the standard error of the mean (SEM).

\section{RESULTS}

Programmed electrical stimulation. On day 4 after myocardial infarction, the presence or absence of underlying myocardial electrical instability was determined by the use of programmed electrical stimulation. In saline-treated animals, programmed electrical stimulation produced nonsustained ventricular tachycardia in six animals and failed to produce ventricular tachycardia in four animals.
Ventricular fibrillation was produced in one dog, thereby eliminating this animal from further study. In drug-treated animals, programmed stimulation performed 12 hours after the second bretylium dose failed to produce ventricular tachycardia in nine animals and produced nonsustained ventricular tachycardia in one animal. This was a significant reduction in the incidence of myocardial electrical instability in the bretylium-treated group $(p=0.027)$. The left ventricular effective refractory period (interventricular septum) in bretyliumtreated animals ( $189 \pm 3$ seconds) was significantly greater $(p<0.01)$ than that observed in salinetreated animals ( $153 \pm 4$ seconds).

Application of current to the intimal surface of the left circumflex coronary artery. An anodal current of 150 $\mu \mathrm{A}$ was applied to the intimal surface of the left circumflex coronary artery via a wire previously inserted into the arterial lumen. In saline-treated animals $(n=10)$, ST segment elevation or depression in excess of $0.3 \mathrm{mV}$ developed at $138 \pm 39$ minutes. Ventricular fibrillation occurred in 9 of 10 animals at $162 \pm 39$ minutes and was preceded by the development of premature ventricular beats at 


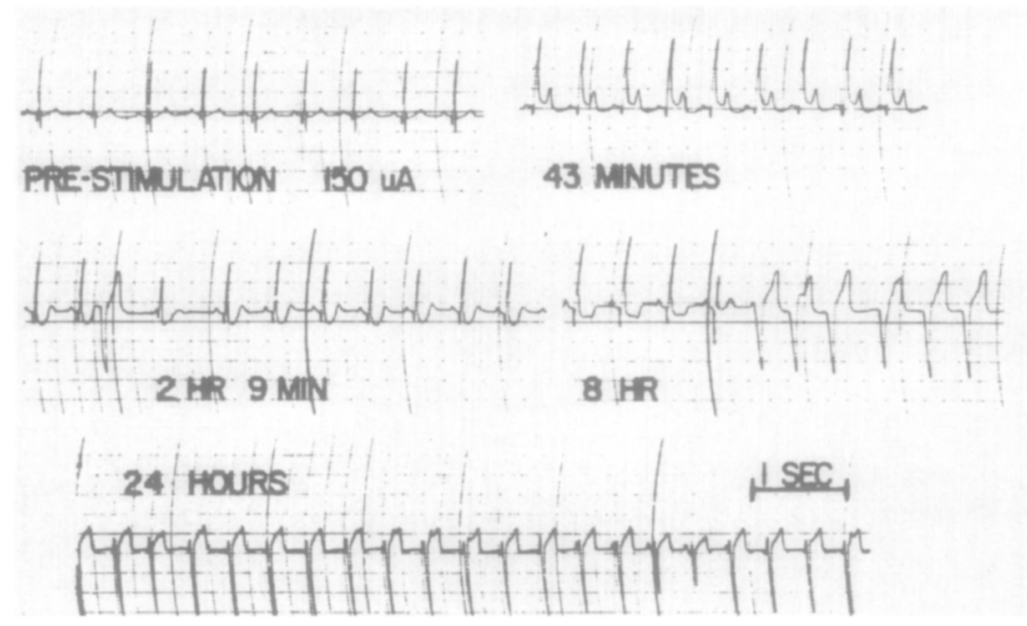

Fig. 2. Effect of chronic bretylium therapy $(10 \mathrm{mg} / \mathrm{kg}$ every $12 \mathrm{hr}$ ). Normal sinus rhythm is present 4 days after anterior myocardial infarction (upper left panel). At 43 minutes, ST segment elevation develops (upper right panel). S'T segment depression and premature ventricular contractions are present at 2 hours, 9 minutes, and at 8 hours (middle panels). At 24 hours, the ECG consists entirely of ventricular premature beats (bottom panel).

$142 \pm 37$ minutes, with development of ventricular tachycardia at $156 \pm 49$ minutes. Representative ECGs from saline-treated animals can be seen in Fig. 1.

In bretylium-treated animals $(\mathbf{n}=10)$, ST segment elevation or depression in excess of $0.3 \mathrm{mV}$ developed at $128 \pm 35$ minutes. Ventricular fibrillation developed in one animal at 16 hours and in a second animal at 9 hours. Two animals died at 42 minutes and 58 minutes, respectively, after the development of bradycardia which led to idioventricular rhythms and electromechanical dissociation. Six animals survived the entire 24-hour protocol. All surviving animals developed posterolateral wall infarction and premature ventricular ectopic beats ( $89 \pm 5 \%$ of all beats at 24 hours). Ventricular tachycardia did not appear in 8 of 10 animals until $286 \pm 37$ minutes after the appearance of ST segment changes. A representative lead II ECG obtained from a bretylium-treated animal is shown in Fig. 2. Bretylium treatment significantly increased survival when compared to saline treatment (Fig. 3).

No significant difference in time to ST segment change was observed between the two treatment groups. The extent of irreversible ischemic injury produced by a 90 -minute occlusion-reperfusion of the left anterior descending coronary artery did not differ between saline $(14.6 \pm 2.2 \mathrm{gm}, 14.1 \pm 2.3 \%$ of left ventricle) and bretylium (15.2 $\pm 2.1 \mathrm{gm}, 15.1 \pm$ $2.1 \%$ of left ventricle) treated groups. In salinetreated animals, irreversible ischemic damage with in the left circumflex coronary artery distribution was not observed except in the one animal surviving the entire 24-hour protocol. Myocardial infarction (16 $\pm 2 \%$ of left ventricular mass) was observed within the left circumflex distribution of all eight animals of the bretylium-treated group which survived 9 or more hours into the experimental protocol.

Intimal injury and occlusive coronary artery thrombi were observed within the left circumflex coronary artery in all 13 animals surviving in excess of 3 hours after electrical stimulation was initiated. Nonocclusive thrombi or an absence of thrombosis was observed in six of seven animals dying prior to 3 hours. Thrombus mass was not different in saline $(10 \pm 4 \mathrm{mg})$ and bretylium $(20 \pm 6 \mathrm{mg})$ treated groups.

\section{DISCUSSION}

Animal models. Epidemiologic ${ }^{12,13}$ and electrophysiologic ${ }^{4.15}$ studies in patients resuscitated from episodes of sudden coronary death have revealed the presence of coronary artery disease and continuing myocardial electrical instability. The search for pharmacologic interventions capable of preventing sudden coronary death has been hampered primarily by a lack of suitable animal models. Most animal models currently used for the study of antiarrhythmic drugs poorly simulate the continuous electrical instability associated with the development of reentrant ventricular arrhythmias and sudden coronary death. Ventricular tachyarrhythmias present 24 to 72 hours after experimental myocardial infarction (the widely used model of Harris ${ }^{16}$ ) rarely proceed to 
ventricular fibrillation. The frequency of ventricular premature beats declines over a period of several days, not representing chronic myocardial electrical instability, with the relative slow rate of ventricular tachycardia resulting from enhanced Purkinje fiber automaticity rather than from localized reentry of myocardial electrical activity. ${ }^{17}$ Reentrant ventricular arrhythmias produced by coronary artery occlusion or reperfusion frequently terminate in ventricular fibrillation. The arrhythmias also poorly simulate the presence of chronic myocardial electrical instability so prevalent in patients resuscitated from episodes of sudden coronary death. Recently it has been shown that ventricular tachyarrhythmias produced in the dog by programmed electrical stimulation 3 to 14 days after myocardial infarction closely resemble those observed in patients rescued from out-of-hospital death. These ventricular tachyarrhythmias can be initiated and terminated with premature ventricular stimuli., $8,9,18-22$ Induction of ventricular tachyarrhythmias is dependent upon local fractionation of electrical activity and delayed activation of ventricular myocardium. Areas of unidirectional block and circuitous delayed activation of isolated segments of ventricular myocardium have been demonstrated. ${ }^{22}$ Continuous diastolic electrical activity has been recorded from areas overlying irreversibly injured ventricular myocardi$\mathrm{um},{ }^{18,19}$ providing further support for the existence of a reentrant mechanism. More importantly, the electrical instability is present over a period of weeks and can result in the development of ventricular fibrillation.

Programmed electrical stimulation. Despite the close similarities in the electrophysiologic and clinical aspects of programmed electrical stimulation in the dog during the subacute phase of myocardial infarction and in patients resuscitated from sudden coronary death, programmed electrical stimulation in the dog differs from the development of sudden coronary death in humans in two major aspects. (1) ECGs recorded from patients at risk for development of sudden coronary death are marked by $a$ high incidence of multiform premature ventricular beats, ventricular couplets, and nonsustained ventricular tachycardia. ${ }^{23,24}$ During the convalescent phase of experimental myocardial infarction in the dog 3 to 14 days after myocardial infarction, spontaneous development of ventricular arrhythmias is rare. (2) Ventricular fibrillation followed by circulatory collapse, the presumed etiology of sudden coronary death, develops spontaneously in humans. In the dog, ventricular fibrillation develops only upon provocation by the electrical induction of premature

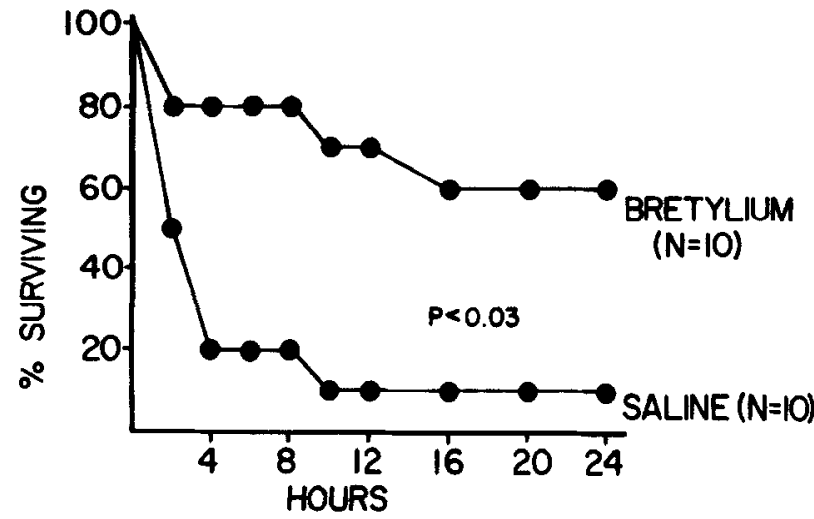

Fig. 3. Effect of bretylium upon survival in a canine model of sudden coronary death. Cummulative survival after time 0 (initiation of current flow to the intimal surface of the left circumflex coronary artery) is shown for saline- and bretylium-treated animals. At 24 hours, bretylium tosylate $(10 \mathrm{mg} / \mathrm{kg}$ every 12 hours) significantly increased $(p<0.03)$ survival compared to the salinetreated group.

ventricular beats. The conscious canine model of sudden coronary death described here spontaneously develops ventricular arrhythmias and ventricular fibrillation when acute myocardial ischemia is produced in the presence of chronic myocardial electrical instability resulting from previous myocardial infarction; this may provide a model which closely simulates the development of ventricular fibrillation in humans. Recent work performed in our laboratory has shown that the increased sensitivity to development of ventricular fibrillation is maintained for more than 30 days after myocardial infarction in the left anterior descending distribution, with ventricular fibrillation developing in seven of seven animals subjected to electrical stimulation of the left circumflex coronary artery intimal surface. Although the animals studied in this report were examined 4 days after myocardial infarction, we believe that comparable mechanisms may be involved when acute ischemia intercedes at later times. Still, it remains difficult to extrapolate these results to humans, since the exact triggers or circumstances responsible for initiation of ventricular fibrillation in humans are unknown. Nevertheless, this study does demonstrate the ability of bretylium to prevent the high incidence of ventricular fibrillation observed when acute ischemia intervenes in the setting of earlier myocardial infarction.

Bretylium electrophysiologic properties. Bretylium exerts both direct effects upon cardiac tissue and indirect effects mediated via its action upon the sympathetic nervous system. Either one or both of these actions may be involved in the ability of 
bretylium to prevent ventricular fibrillation in the conscious canine model we have described. The direct action of bretylium upon cardiac tissue is to increase action potential duration, an effect most prominently exhibited in ventricular myocardium. ${ }^{25,26}$ This action was probably responsible for the significantly larger effective refractory periods observed in the bretylium-treated animals, and may be the mechanism by which bretylium prevents the induction of ventricular tachyarrhythmias in response to programmed electrical stimulation during the recovery phase of experimental myocardial infarction. ${ }^{8,9}$

The acute administration of bretylium releases catecholamines from sympathetic nerve terminals. ${ }^{27}$ After uptake into sympathetic nerve terminals, bretylium inhibits catecholamine release caused by sympathetic nervous system stimulation., 27 The release of catecholamines from sympathetic nerve terminals can cause hyperpolarization of damaged cardiac cell fibers and can improve myocardial conduction., ${ }^{8,26}$ This action of bretylium has also been suggested as a possible mechanism for its antifibrillatory action. ${ }^{26}$ However, inhibition of norepinephrine release from sympathetic nerve terminals may be involved in the ability of bretylium to prevent ventricular fibrillation resulting from acute myocardial ischemia in the presence of prior myocardial infarction. Swartz and Stone ${ }^{28}$ have shown that left stellate ganglionectomy lowers the incidence of ventricular fibrillation produced by a short-term occlusion-reperfusion of the left circumflex coronary artery in the presence of previous myocardial infarction. Interruption of sympathetic nerve release of norepinephrine in the heart may have prevented myocardial electrical instability in our experiments and may be a factor in bretylium's antifibrillatory action.

Conclusions. Recent advances in our knowledge concerning risk factors associated with the development of ventricular fibrillation during the post hospital phase of myocardial infarction have enhanced our ability to identify groups of patients at high risk for the development of sudden coronary death. $^{23,24}$ The identification of efficacious antifibrillatory compounds such as bretylium tosylate through the use of appropriate animal models may help identify effective pharmacologic interventions capable of reducing mortality in these high risk patients. The antifibrillatory actions of bretylium tosylate make this drug a serious candidate for continued study in humans to determine its efficacy in reducing the risk for sudden coronary death.

\section{REFERENCES}

1. Bacaner MB: Bretylium tosylate for suppression of induced ventricular fibrillation. Am J Cardiol 17:528, 1966.

2. Kniffen FJ, Lomas TE, Counsell RE, Lucchesi BR: The antiarrhythmic and antifibrillatory actions of bretylium and its o-iodobenzyltrimethylammonium analog, UM-360. .] Pharmacol Exp Ther 192:120, 1975.

3. Bacaner BM. Schrienemachers D: Bretylium tosylate for suppression of ventricular fibrillation after experimental ventricular fibrillation. Nature 220:494, 1968.

4. Anderson JL, Patterson E, Conlon M, Pasyk S, Pitt B, Lucchesi BR: Kinetics of antifibrillatory effects of bretylium: Correlation with myocardial drug concentrations. Am J Car diol 46:583, 1980 .

5. Bacaner MB: Treatment of ventricular fibrillation and other acute arrhythmias with bretylium tosylate. Am J Cardio 21:530, 1968

6. 'Terry G, Vellani CW, Higgins MR, Doig A: Bretylium tosylate in treatment of refractory ventricular arrhythmias complicating myocardial infarction. Br Heart J 32:21, 1970.

7. Dhurandhar RW, Teasdale SJ, Mahon WA: Bretylium tosylate in the management of refractory ventricular fibrillation. Can Med Assoc J 105:161, 1971

8. Patterson E. Gibson JK, Lucchesi BR: Postmyocardial infarction reentrant ventricular arrhythmias in conscious dogs: Suppression by bretylium tosylate. J Pharmacol Exp Ther 216:453, 1981

9. Patterson E, Gibson JK, Lucchesi BR: Prevention of chronic canine ventricular tachyarrhythmias with bretylium tosylate. Circulation 64:1045, 1981.

10. Patterson F, Holland K, Eller BT, Lucchesi BR: Ventricular fibrillation resulting from ischemia at a site remote from previous myocardial infarction. A conscious canine model of sudden coronary death. Am J Cardiol 50:1414, 1982.

11. Stewart JR, Gibson JK, Pitt B, Lucchesi BR: Postinfarction arrhythmias in the conscious dog: Electrophysiologic observations. Circulation 60(suppl II):159, 1979.

12. Weaver WD, Lorch GS, Alvarez HA, Cobb LA: Angiographic findings and prognostic indicators in patients resuscitated from sudden cardiac death. Circulation 54:895, 1976.

13. Liberthson RR, Nagel EL, Hirschmann JC, Nussenfeld SR, Blackbourne DB, Davis .JM: Pathophysiologic observations in prehospital ventricular fibrillation and sudden cardiac death. Circulation 49:790, 1974.

14. Josephson ME, Horowitz LN, Spielman SR, Greenspan AM: Electrophysiologic and hemodynamic studies in patients resuscitated from cardiac arrest. Am J Cardiol 46:948, 1980.

15. Ruskin JN, DiMarco JP, Garan H: Out-of-hospital cardiac arrest: Electrophysiologic observations and selection of longterm antiarrhythmic therapy. N Engl J Med 303:607, 1980.

16. Harris AS: Delayed development of ventricular ectopic rhythms following experimental coronary occlusion. Circulation 1:1318, 1950 .

17. Lazzara R, El-Sherif N, Hope RR, Scherlag BJ: Ventricular arrhythmias and electrophysiological consequences of myocardial infarction. Circ Res 42:740, 1978.

18. El-Sherif N, Hope RR, Scherlag BJ, Lazzara R: Reentrant ventricular arrhythmias in the late myocardial infarction period. 2. Patterns of initiation and termination of reentry. Circulation 55:702, 1977

19. Gibson JK, Lucchesi BR: Electrophysiologic actions of UM272 (Pranolium) on reentrant ventricular arrhythmias in post-infarction canine myocardium. J Pharmacol Exp Ther 214:247, 1980

20. Karaguezian HS, Fenoglio JJ, Weiss MB, Wit AL: Protracted ventricular tachycardia induced by premature stimulation of the canine heart after coronary artery occlusion and reperfusion. Circ Res 44:833, 1979.

21. Michelson EL, Spear JF, Moore EN: Electrophysiologic and 
anatomic correlates of sustained ventricular tachyarrhythmias in a model of chronic myocardial infarction. Am J Cardiol 45:583, 1980.

22. El-Sherif N, Smith A, Evans K: Canine ventricular arrhythmias in the late myocardial infarction period. 8. Epicardial mapping of reentrant circuits. Circ Res 49:255, 1981.

23. Ruberman W, Weinblatt E, Goldberg JD, Frank CW, Shapiro S: Ventricular premature beats and mortality after myocardial infarction. N Engl J Med 297:750, 1977.

24. Ruberman W, Weinblatt E, Goldberg JD, Frank CW, Chaudhary BS, Shapiro S: Ventricular premature complexes and sudden death after myocardial infarction. Circulation 64:297, 1981.

25. Wit AL, Steiner C, Damato AN: Electrophysiological effects of bretylium tosylate on single fibers of the canine specialized conduction system and ventricle. I Pharmacol Exp Ther 173:344, 1970.

26. Bigger JT, Jaffe CC: The effect of bretylium tosylate on electrophysiologic properties of ventricular muscle and Purkinje fibers. Am J Cardiol 27:82, 1971.

27. Boura ALA, Green AF: The action of bretylium: Adrenergic neuron blocking and other effects. Br J Pharmacol 14:536, 1959.

28. Swartz PJ, Stone HL: Left stellectomy in the prevention of ventricular fibrillation caused by acute myocardial ischemia in conscious dogs with anterior myocardial infarction. Circulation 62:1256, 1980 .

\title{
Failure of bretylium to suppress inducible ventricular tachycardia
}

\begin{abstract}
Five patients with recurrent, life-threatening ventricular arrhythmias were given bretylium tosylate intravenously for a minimum of 4 deys. Arrhythmias were not related to acute ischemia in any patient. Four patients had inducible ventricular tachycardia, and one patient had inducible ventricular fibrillation requiring cardioversion while taking no medications. Programmed electrical stimulation was then repeated to assess the ability of bretylium to suppress inducible ventricular tachycardia. Bretylium tosylate, at a mean dose of $\mathbf{2 . 3} \mathbf{~ m g}$ intravenously per minute, did not suppress inducible ventricular arrhythmias in any patient. Rapid ventricular tachycardia was induced in all patients, and ventricular fibrillation was induced in one patient. Two patients required external cardioversion to terminate their arrhythmias. Bretylium tosylate, given in relatively large doses chronically, did not suppress inducible ventricular arrhythmias in these five otherwise drug-refractory patients with chronic recurrent ventricular tachycardia. This failure to suppress inducible ventricular arrhythmias cannot be attributed to the initial catecholamine release which occurs in the first hour or two after the drug is administered. (AM HEART J 105:717, 1983.)
\end{abstract}

H. Leon Greene, M.D., Jeffrey A. Werner, M.D., Brian W. Gross, M.D., and Gena K. Sears, R.N. Seattle, Wash.

Bretylium tosylate is an antiarrhythmic drug which can be categorized as a Vaughan-Williams type III agent. ${ }^{1}$ It increases the ventricular fibrillation threshold ${ }^{2}$ and prolongs action potential duration and the effective refractory period without much effect on the rate of rise of the cardiac action

From the Division of Cardiology, Department of Medicine, Harborview Medical Center, University of Washington.

Supported in part by Grant HL 18805 from the National Heart, Lung, and Blood Institute, Bethesda, MD.

Received for publication May 27, 1982; revision received July 26, 1982; accepted Sept. 8, 1982.

Reprint requests: H. Leon Greene, M.D., Division of Cardiology (ZA-35), 3259 th Ave., Seattle, WA 98104. potential. ${ }^{3}$ Bretylium is indicated for treatment of ventricular fibrillation, prophylaxis against ventricular fibrillation, or treatment of ventricular tachycardia after failure of a first-line drug.

Intracardiac electrophysiologic studies are routinely performed to assist in the choice of antiarrhythmic therapy for patients with ventricular dysrhythmias. ${ }^{4-6}$ The ability of an antiarrhythmic agent to suppress arrhythmia induction with these techniques is predictive of long-term success of that agent. However, certain drugs, while remaining effective clinically, do not suppress inducible ventricular arrhythmias. ${ }^{7-8}$ Amiodarone, also a type III drug, is useful clinically and suppresses spontaneous 